\title{
ENZYME-LINKED IMMUNOSORBENT ASSAY DETECTION FOR MALIGNANCY USING ANTI-P53 ANTIBODIES
}

\author{
Muhanna M. Al-Shaibani ${ }^{1,2}$, Radin Maya Saphira Radin Mohamed ${ }^{1, *}$, Ishak Mat ${ }^{2}$, Adel Al-Gheethi ${ }^{1}$ and \\ Jacinta Santhanam ${ }^{3}$. \\ 1 Micro-pollutant Research Centre (MPRC), Department of Water and Environmental Engineering, Faculty of Civil \\ Engineering and Built Environment, Universiti Tun Hussein Onn Malaysia, 86400 Parit Raja, Johor, Malaysia. \\ ${ }^{A}$ Advanced Medical and Dental Institute, Universiti Sains Malaysia, Bandar Putra Bertam, Kepala Batas, Penang 13200 , \\ Malaysia. \\ ${ }^{3}$ Centre for Toxicology and Health Risk Studies, Faculty of Health Sciences, Universiti Kebangsaan Malaysia, Jalan \\ Raja Muda \\ Abdul Aziz, 50300 Kuala Lumpur, Malaysia.
}

Corresponding author: Radin Maya Saphira Radin Mohamed

Email: maya@uthm.edu.my

\begin{abstract}
Tumour protein 53 (p53) plays an important role in the instruction of the cell cycle. In a variety of transformed cell lines, tumour protein is expressed in high amounts, and it is believed to contribute to transformation and malignancy. This research aimed to detect the anti-p53 antibodies in sera of patients with various malignant tumours and to evaluate the sensitivity and specificity of an enzyme-linked immunosorbent assay (ELISA). A case-control study was conducted on samples from 49 patients with various types of malignant tumours at Sultanah Bahiyah Hospital, Alor Setar, Kedah, Malaysia, and 32 healthy control cases with non-malignant disease collected from Universiti Sains Malaysia clinic, Penang, Malaysia. The antibodies against p53 protein in the serum samples were analysed using the commercial ELISA kit, Calbiochem ${ }^{\circledR}$ p53- ELISAPLUS. The results showed that the rate of anti-p53 antibodies in patients with various malignant tumours was 13 out of 49 (26.5\%), compared with only 2 out of $32(6.25 \%)$ in healthy controls $(p<0.001)$. The sensitivity of this kit reached $28.6 \%$ and the specificity was $93.8 \%$. In conclusion, these results suggest that the anti-p53 antibodies can be detected in different sera of malignant tumour patients and the ELISA kit is highly specific; nevertheless, its discrimination power is not perfect because of its low sensitivity to determine the anti-p53 antibodies.
\end{abstract}

Keywords: p53 gene, serum anti-p53 antibodies, ELISA, malignant tumours, Natural autoantibodies.

\section{INTRODUCTION}

The tumour suppressor protein 53 , or tumour protein 53 (p53), is a phosphoprotein present in low amount in the nucleus of the normal cells, and the p53 gene is located on the short arm of chromosome 17. The p53 protein is 393 amino acids long and has seven domains. It is an approximately 53-kilo Dalton nuclear phosphoprotein, which normally plays the role of tumour suppressor and as an intermediary of natural cell death ${ }^{1}$.

The tumour suppressor protein inhibits mitosis ${ }^{2}$. The role of $\mathrm{p} 53$ in binding to oncovirus proteins was discovered in 1979 in a study of tumourassociated antigens ${ }^{3}$. The wild-type p53 acts to suppress uncontrolled outgrowth of aberrant cells, by inducing cell cycle arrest, DNA repair or programmed death, and triggers apoptosis via multiple pathways ${ }^{4}$. Besides, p53 is a transcription factor that activates vital damage containment procedures in response to DNA damage, oncogene activation, hypoxia, and the loss of normal cell contacts ${ }^{5}$. Natural autoantibodies (NAbs) are an original part of the immune system, originating from B1-cells, and are mainly of IgM isotype, which have generally low binding affinity. NAbs complete important and diverse immunological roles, providing very early innate immune protection to ensure removal of possible autoantigens by scavenging dead or apoptotic cellular debris, and they might improve cardiovascular profile ${ }^{6}$.

Usually the immune system can recognise selfforeign substances and ignore the body's selfcells, so one or more autoantibodies may be produced by a person's immune system when it fails to distinguish between self and non-selfproteins ${ }^{7,8}$. Anti-p53 antibodies (p53-Abs) serve as markers for established or even incipient tumours. However, p53 accumulation may occur in non-tumour cells under various forms of stress such as autoimmune disease ${ }^{9,10}$. The p53-Abs also differ in the quantity and titration between autoimmune diseases and malignant tumour patients ${ }^{11}$. In addition, it is found mostly in various malignant tumour patients with a specificity of $96 \%{ }^{12}$. Different studies have shown that p53 mutations may occur early in the transformation of some cancers, which made it a suitable tool for early cancer detection ${ }^{13}$.

The increasing p53 protein in tumour cells is indicative of a mutated p53 gene, and the increased level of p53 may elicit an immune 
response, resulting in p53-Abs in serum ${ }^{14}$. Therefore, the present study aimed to detect p53Abs in the serum of patients with various malignant tumours, and to evaluate the sensitivity and specificity of an enzyme-linked immunosorbent assays (ELISA) for its detection.

\section{MATERIALS and METHODS}

\section{Study population}

The research and ethics committee of the Advanced Medical and Dental Institute (IPPT), Universiti Sains Malaysia (USM) approved the present study. The approval number is 3285 /IPPT, USM. It was performed as a case control study that compares between two groups; a non-healthy group and a healthy control group. The sample size was selected according to some previous studies 15. A total of 49 cases as a non-healthy group with various histologically defined malignant conditions in the early stage were collected from Sultanah Bahiyah Hospital, Bandar Alor Setar, Kedah, Malaysia (male, $n=25$, female, $\mathrm{n}=24$ ) with the age between 27 and 79 years (mean age 56.3 years). The malignancies included breast cancer 11 cases, colorectal cancer 13 cases, ovarian cancer 11 cases, bladder cancer 3 cases, and one case was suffering from testicular cancer. Besides, one case was identified as rectal cancer, and nine cases were suffering from other chronic diseases such as liver cirrhosis, chronic hepatitis, septicaemia, an ectopic pregnancy, head diseases, Parkinson's disease, and polycythaemia.

The exclusion criteria for non-healthy group were positive HIV, HBV and HCV patients as well as the last stage of malignancy. A population of 32 with well-defined ethnic background received routine physical examination, and they constituted the control group. The blood samples of the healthy control group were collected from the management team and nurseing staff of the Pusat Kesihatan clinic at Universiti Sains Malaysia (USM), Pulau Penang Island, Malaysia after informed consent was obtained. Samples were matched according to ethnicity and geographic locations to form the control cases of the study.

None of the controls had any personal history of cancer at the time of routine physical examination. The inclusion criteria of the healthy control group were for any healthy person, aged between 22-62 years (mean age 40.7 years), and who is not on regular medication to avoid any drug interaction. The exclusion criteria of non-healthy group and control group were positive HIV, HBV and HCV patients to prevent risk of infection of the research team; furthermore, psychiatric illness and palliative cases were also excluded to avoid the adverse effect of any drug interaction with the test. Data Sheet for non-healthy and healthy control group was presented as supplementary data (SD), Table SD 1 \& Figure SD1. Calibration curve show that an antibody titer in units can be assigned to the unknown sample when assayed in parallel with a calibration curve. Dilution of $1: 1.5,1: 2,1: 3,1: 4$ and $1: 6$ of the calibrator results in a curve with $0.16,0.25,0.33$, 0.5 , and $0.67 \mathrm{U}$. The undiluted calibrator represents $1 \mathrm{U}$.

\section{Sample Collection and Preparation}

Around 5 to $7 \mathrm{~mL}$ of venous blood samples were obtained from each patient and volunteer control group by specialist nurses in the hospital Sultanah Bahiyah and USM clinic respectively. The blood was collected in a tube without any additives. All sera were obtained after complete clotting by centrifugation, and were immediately frozen and stored at $-20^{\circ} \mathrm{C}$ until used.

\section{Enzyme Linked Immunosorbent Assay (ELISA) method}

Anti-p53 autoantibody titer was measured using a sandwich-type p53 ELISAPLUS (Autoantibody) Kit (Calbiochem, Darmstadt, Germany). The Sera from 49 patients and 32 controls were analysed according to manufacturer's protocols. Briefly, subjects' sera were diluted 100 times and incubated for 1 hour at room temperature alongside manufacturer-provided calibrators (at concentrations of $1.0,0.67,0.5,0.33$ and 0.16 ) and negative control in a microtiter plate precoated with human recombinant wild-type p53.

All samples were analysed in duplicate, and the plate was washed five times before a secondary peroxidase-conjugated anti-human IgG antibody was added and incubated for 1 hour at room temperature. After subsequent further five washes, visualization was performed by adding TMB (3, 5, 5 tetramethylbenzidine) and incubation for $30 \mathrm{~min}$ in the dark. The reaction was stopped with addition of stop solution, $2 \mathrm{M}$ hydrochloric acid, $(2 \mathrm{M} \mathrm{HCl})$. The colour reaction absorption was measured directly after addition of the stop solution at dual wavelengths of $A_{450} \mathrm{~nm}$ and $A_{595} \mathrm{~nm}$ using the power WaveXs spectrophotometer, USA.

The yellow colour formed is proportional to the concentration of serum p53-Abs. In addition, the p53-Abs were quantified using the Absorbance (A) at optical density (O.D) and a standard curve was plotted, employing the control serum provided by the manufacturer. The cut-off value was established using the $\mathrm{OD}$ value of the negative control. The samples with OD within $(20 \%)$ of the $O D$ of the negative control were classed as antip53 autoantibody negative, according to the manufacturer's protocol as presented in Figure 1.

\section{Statistical analysis}

The Statistical analysis was performed using IBM ${ }^{\circledR}$ SPSS $\circledast$ Statistics-20. Comparison of group percentages and constituent ratios were analyzed using Fisher exact test, Student $\mathrm{t}$ Chi-squared tests $\left(\mathrm{x}^{2}\right)$, while Mann-Whitney rank-sum tests were used to determine the significant difference 
between the two groups. The $p \leq 0.05$ was considered significant between autoantibodies measurements in the sera of the various malignant tumour patient and normal control group. The results were interpreted with the calculated cut-off value. The negative samples were all the sera with an absorbance less than or equal to the cut-off value. The positive samples were all the sera with an absorbance greater than the cut-off value. The critical cases were above the cut-off value of the critical area $(A+20 \%)$. If the calculated cut-off is 0.15 , the critical range lies between $A_{450} \mathrm{~nm}=(0.426$ to 0.630$)$, serum samples, which show an absorbance and lie in the critical range, should be retested. If they have a critical absorption again, patients should be sampled 5-8 weeks later.

\section{RESULTS}

The results from the current work showed that, out of 49 cases, there were 13 positive cases for Abs to p53 in the sera of patients with various malignant tumours. The positive cases were distributed as follows, (4/11) $36.36 \%$ were detected from breast cancer patients, (5/13) $38.46 \%$ from colorectal cancer and (3/11) $27.3 \%$ ovarian cancer as shown in Table 1.

Among the breast cancer patients, only four positive cases were detected, in which three subjects were pre-operation and one case as postoperation and post-chemotherapy. The other seven cases were negative for p53-Abs, with mean age of 54.5 years for all cases. The detection of p53-Abs in ovarian cancer cases resulted with only three positive cases, detected from 11 cases, with the mean age of 54.4 years for all cases. The distribution of p53-Abs in colorectal cancer cases were five positive cases detected from 13 cases, with mean age of 60.5 years for all cases. One positive case of p53-Abs was detected from 3 bladder cancer patients. In addition, p53-Abs were not detected in the serum of the 11 cases suffering from testicular cancer, rectal cancer and various other chronic diseases such as liver cirrhosis, chronic hepatitis, septicaemia, ectopic pregnancy, head diseases, Parkinson's disease and polycythaemia.

A total of 30 subjects from 32 control volunteers' cases were negative for p53-Abs in their serum. However, only two subjects were recognised as positive for p53-Abs with O.D greater than the cut-off value. The results from this study found that, the positive rates of p53-Abs in the malignant tumour group were significantly higher than normal control group ( $p \leq 0.001)$. In addition, the statistical analysis showed that there was a significant difference between breast cancer positive cases and negative control at $p \leq 0.001$, colorectal cancer at $p \leq 0.05$ and control. While there was no significant difference for ovarian cancer and other disease when compared with the control group as shown in Table 2.

Table 1: Anti-p53 antibody positive cases from all types of cancer, with serum O.D and antibody titer measured using Calbiochem ${ }^{\circledR}$ p53- ELISA ${ }^{\text {PLUS }}$ (Autoantibody) kit

\begin{tabular}{|c|c|c|c|c|}
\hline No. & $\begin{array}{l}\text { Type of } \\
\text { cancer }\end{array}$ & $\begin{array}{c}\text { Age } \\
\text { (years) }\end{array}$ & $\begin{array}{c}\text { OD at } \\
\mathrm{A}_{450} \\
\mathrm{~nm}\end{array}$ & $\begin{array}{l}\text { Titer } \\
\text { U/mL }\end{array}$ \\
\hline 1 & $\begin{array}{l}\text { Breast } \\
\text { cancer pre- } \\
\text { operation } \\
\text { Breast }\end{array}$ & 43 & 1.625 & 0.74 \\
\hline 2 & $\begin{array}{l}\text { cancer pre- } \\
\text { operation } \\
\text { Breast }\end{array}$ & 52 & 1.080 & 0.87 \\
\hline 3 & $\begin{array}{l}\text { cancer pre- } \\
\text { operation } \\
\text { Breast }\end{array}$ & 66 & 1.109 & 0.65 \\
\hline 4 & $\begin{array}{l}\text { cancer } \\
\text { post- } \\
\text { operation }\end{array}$ & 43 & 1.435 & 0.63 \\
\hline 5 & $\begin{array}{l}\text { Colorectal } \\
\text { cancer }\end{array}$ & 75 & 0.971 & 0.48 \\
\hline 6 & $\begin{array}{l}\text { Colorectal } \\
\text { cancer }\end{array}$ & 54 & 0.856 & 0.38 \\
\hline 7 & $\begin{array}{l}\text { Colorectal } \\
\text { cancer }\end{array}$ & 72 & 4.000 & $>1$ \\
\hline 8 & $\begin{array}{l}\text { Colorectal } \\
\text { cancer }\end{array}$ & 64 & 1.093 & 0.97 \\
\hline 9 & $\begin{array}{l}\text { Colorectal } \\
\text { cancer }\end{array}$ & 66 & 2.051 & 0.64 \\
\hline 10 & $\begin{array}{l}\text { Ovarian } \\
\text { cancer }\end{array}$ & 49 & 0.929 & 0.43 \\
\hline 11 & $\begin{array}{l}\text { Ovarian } \\
\text { cancer }\end{array}$ & 71 & 0.860 & 0.87 \\
\hline 12 & $\begin{array}{l}\text { Ovarian } \\
\text { cancer }\end{array}$ & 71 & 2.200 & 0.69 \\
\hline 13 & $\begin{array}{l}\text { Bladder } \\
\text { cancer }\end{array}$ & 79 & 1.099 & 0.89 \\
\hline 14 & $\begin{array}{l}\text { Undiluted } \\
\text { standard }\end{array}$ & $======$ & 2.868 & 1.00 \\
\hline
\end{tabular}




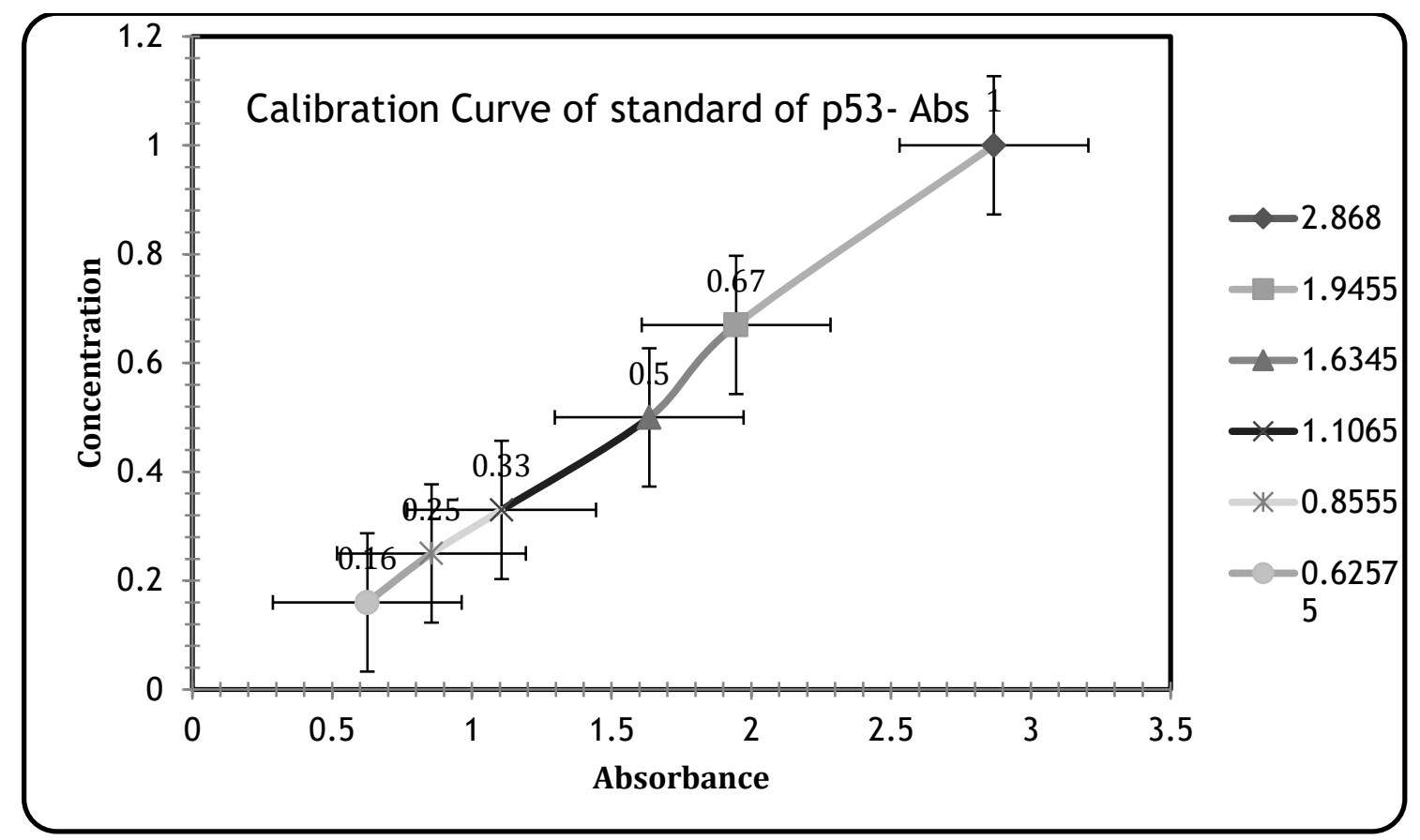

Figure 1 : Calibration curve of p53-Abs

Table 2: Comparison of serum anti-p53 antibody values between all cancer groups and healthy control group

\begin{tabular}{lcccc}
\hline Type & N & $\begin{array}{c}\text { Mean O. D } \\
\mathbf{A}_{450} \mathbf{~ n m}\end{array}$ & Std. Deviation & P-Value \\
\hline Breast cancer & 11 & 0.527 & 0.58781 & $\leq 0.001^{*}$ \\
Colorectal cancer & 13 & 0.772 & 1.08184 & $\leq 0.001^{*}$ \\
Ovarian cancer & 11 & 0.461 & 0.24400 & 0.221 \\
Others & 14 & 1.066 & 0.03693 & 0.245 \\
healthy controls & 32 & 0.150 & 0.17546 & $\cdots$ \\
\hline
\end{tabular}

*Significant difference compared to healthy control group.

In this study, the mean age of control group was 40.7 years, and the mean age of colorectal patients was 60.5 years. While the mean age of breast and ovarian cancer cases were 54.5 and 54.4 years respectively.
There was no significant correlation of p53-Abs with patient age, sex, and pathological parameters. However, there was a significant difference between the age of the control group and the age of the other types of malignant tumour cases as shown in Table 3.

Table 3: Distribution of mean age for all cancer groups

\begin{tabular}{lcccc}
\hline Type of cancer & $\mathbf{N}$ & $\begin{array}{c}\text { Mean O. D } \\
\mathbf{A}_{450} \mathrm{~nm}\end{array}$ & Mean of age & $P$-Value \\
\hline Breast Cancer & 11 & 0.527 & 54.5 & 0.030 \\
Colorectal Cancer & 13 & 0.772 & 60.5 & $<0.001$ \\
Ovarian Cancer & 11 & 0.461 & 54.4 & 0.033 \\
Others & 14 & 1.066 & 55.4 & $<0.001^{*}$ \\
healthy controls & 32 & 0.150 & 40.7 & 0.008 \\
\hline
\end{tabular}

*Significant difference compared to healthy control group.

\section{DISCUSSION}

Antibodies are produced in response to a foreign protein or substance within the body, especially pathogens. Normally, the immune system is capable of recognising and disregarding the body's own cells and to not over react to non- threatening substance in the environment such as food ${ }^{16}$. The immune system may fail to recognize one or more of the body's normal constituents as self, leading to production of autoantibodies ${ }^{17}$. Cancer is immunogenic, and various tumour antigens are found inside the body of cancer patient; however, now it is possible to utilize the 
immune response elicited by cancer growth as a potential diagnostic tool ${ }^{18}$. This study showed that, the production level of p53-Abs to the p53 is diverse according to the type of cancer and the power of immune system of each individual to determine the mutated protein due to cancer formation.

In the present research, 49 serum samples were investigated to detect the level of p53-Abs from patients, suffering from different types of cancer disease and some other chronic diseases such as liver cirrhosis, chronic hepatitis, septicemia, an ectopic pregnancy, head diseases, Parkinson's disease, and polycythemia. The p53-Abs were detected in 13/49 serum samples which represent around $26.5 \%$ with sensitivity range between 7 to $38 \%$ in the sera of the patients with different types of tumour. The highest positivity rate was observed in colorectal cancer cases (38\%) followed by the breast cancer cases (36\%). A previous study reported that the mutation of the p53 tumour suppressor gene, overexertion, serum p53 antibodies and p53 protein in tumour tissue, had been encountered in different types of human malignancies $^{19}$.

In addition, this may be strongly associated with tumour and with p53 protein accumulation, indicating that this immune response is triggered by the accumulation of p53 ${ }^{20}$.

The results of this study are in accordance with another study that showed the highest prevalence of p53-Abs in sera of breast cancer and colorectal cancer ${ }^{21}$. While it was only $27.3 \%$ in the ovarian cancer, this may be due to the different anatomy of ovaries, or those patients may be with advanced stages of ovarian cancer, so the immune system functionality is lower compared with normal 22. Furthermore, the uncharacterised protein-protein interactions between $\mathrm{p} 53$ protein and other proteins present in serum might cause false-negative results in the detection of circulating antibodies to this type of protein, or the immune system cannot detect the proteinprotein interaction due to that mask. Previous studies indicated that the ascites p53-Abs in ovarian cancer is more significant than serum ${ }^{23}$. The first description of p53-Abs in sera of patients with breast cancer was in 1982 which was detected using western blotting 24,25 .

Similarly, numerous studies have been performed in breast cancer; the findings showed that the frequency of p53-Abs ranged from 15 to $20 \%$. Most of these studies were done in the USA and Europe, by using ELISA method ${ }^{26}$. Furthermore, several studies have been carried out with various techniques, demonstrating that the detection rates of p53-Abs were between 14-31\% in colorectal cancer 10,27 . Moreover, other previous studies reported that the detection rate of $\mathrm{p53}$ $\mathrm{Ab}$ in breast cancer was between $10-26 \% 28,29$, and in gastric cancer it was between $12-19 \% 30,31$.
Besides, detection of p53-Abs in the oesophageal cancer was at $25 \%{ }^{32}$. Moreover, $20.4 \%$ of lung cancer patients have positive levels of p53-Abs detected by ELISA ${ }^{33}$. In pancreatic cancer, the positivity of p53-Abs was $6 \%{ }^{34}$. Our results show that $38.5 \%$ of colorectal cancer have positive levels of p53-Abs. The 30/32 subjects from healthy control volunteers were documented as negative for p53-Abs in their serum. Nevertheless, it is important to keep in mind that in some cases p53-Ab can be detected in patients without cancer disease; for example, in our study we detected two cases from healthy control group, $(2 / 32) 6.25 \%$ was positive for p53-Ab with titer higher than cut-off values. This may be due to the subject having silent malignancy or may be due to bias during the data collection, which can be confirmed by the use of other tumour marker with intensive follow-up.

Numerous studies have reported that serum p53 $\mathrm{Ab}$ was detected previously in different populations that were at increased risk for developing malignant disease ${ }^{35}$. Moreover, from this study, it was clear that the production of these antibodies is limited to a minority of tumour patients. Moreover, it was found that the ELISA kit is not useful for diagnosis of tumour because of its low sensitivity to detect the level of the p53-Abs, which is not suitable for preoperative tumour marker. However, the ELISA kit has revealed a high specificity (97\%) according to the findings of this study and previous literature 36,37 . Additionally, the present study shows that p53Abs can be detected before diagnosis in a cohort of randomly selected normal-risk individuals. Our results were similar to a previous study that reported the detection of anti-bodies specific to p53 protein in healthy volunteers ${ }^{38}$. Furthermore, the intensive follow-up will be required to screen the subclinical potential of malignant tumours in the healthy control group ${ }^{37}$. We could regard this as the first analysis of anti-p53 autoantibodies in Malaysia and the value of anti-p53 antibody may be as a biomarker.

\section{CONCLUSION}

Our findings suggest that surveillance of p53-Abs is useful in detecting various types of malignant tumours and may be of value in cancer screening. Anti-p53 autoantibody is potentially useful in patient monitoring during therapeutic follow-up after post-operative malignant tumours, since the drop in the level of p53-Abs may be the result of complete tumour removal and successful chemotherapy. In addition, due to high specificity (97\%) of ELISA kit for p53-Abs, it may be used to monitor the relapse of cancer after surgery and chemotherapy together with other tumour markers to increase sensitivity of monitoring of some malignancies. 


\section{ACKNOWLEDGEMENTS}

Researchers express their appreciation to the Advance Medical and Dental Institute (AMDI) IPPT for grant support and to all scientific officers for their cooperation during research. Special thanks to the Department of Pathology of Hospital Sultanah Bahiyiah and to the Pusat Kesihatan, USM for kindly assisting in sample collection. Researchers also would like to show their sincere gratitude to the Universiti Tun Hussein Onn Malaysia, Faculty of Civil Engineering and Built Environment for supporting grant. The authors would like to thank the Ministry of Education Malaysia (KPM) for providing the Fundamental Research Grant Scheme (FRGS).

\section{ETHICAL STATEMENT}

Advanced Medical and Dental Institute (AMDI) (IPPT) approved this study. The approval number is $3285 /$ IPPT, USM.

\section{CONFLICT of INTEREST}

The authors declare no potential conflict of interest.

\section{FUNDING AND SUPPORT}

This research was supported by Advanced Medical and Dental Institute (AMDI) or (IPPT) grant USM, Kepala Batas, Penang, Malaysia and from the Ministry of Education (Kementerian Pendidikan Malaysia)(KPM) for providing the Fundamental Research Grant Scheme (FRGS) with reference code: FRGS/1/2019/WAB05/UTHM/02/5.

\section{REFERENCES}

1. Yue X, Zhao $Y, X u Y$, Zheng $M$, Feng Z, Hu W. Mutant p53 in cancer: accumulation, gain-of-function, and therapy. $\mathrm{J} \mathrm{Mol} \mathrm{Biol}$ 2017; 429(11):1595-606.

2. Flórez M, Fêo HB, Da Silva G, Yamatogi RS, Aguiar A, Araújo Jr J, et al. Cell cycle kinetics, apoptosis rates and gene expressions of MDR-1, TP53, BCL-2 and $\mathrm{BAX}$ in transmissible venereal tumour cells and their association with therapy response. Vet Comp Oncol 2017; 15(3):793-807.

3. Katano H. Pathological Features of Kaposi's Sarcoma-Associated Herpesvirus Infection. Adv Exp Med Biol 2018; 1045:357-376.

4. Chen J. The cell-cycle arrest and apoptotic functions of p53 in tumor initiation and progression. Cold Spring Harb. Perspect Med 2016; 6(3):a026104.

5. Walia S, Kamal R, Dhawan D, Kanwar S. Chemoprevention by probiotics during 1 , 2-dimethylhydrazine-induced colon carcinogenesis in rats. Dig Dis Sci 2018; 63(4):900-9.
6. Kearney JF, Patel P, Stefanov EK, King RG. Natural antibody repertoires: development and functional role in inhibiting allergic airway disease. Annu Rev Immunol 2015; 33:475-504.

7. Koneczny I, Herbst R. Myasthenia gravis: pathogenic effects of autoantibodies on neuromuscular architecture. Cells 2019; 8(7):671.

8. AbuSara NF, Piercey BM, Moore MA, Shaikh AA, Nothias L-F, Srivastava SK, et al. Comparative genomics and metabolomics analyses of clavulanic acid-producing Streptomyces species provides insight into specialized metabolism. Front Microbiol 2019; 10:2550.

9. Yu G, Luo $H$, Zhang $N$, Wang $Y$, Li $Y$, Huang $\mathrm{H}$, et al. Loss of p53 sensitizes cells to palmitic acid-induced apoptosis by reactive oxygen species accumulation. Int J Mol Sci 2019; 20(24):6268.

10. Shimada H. p53 molecular approach to diagnosis and treatment of esophageal squamous cell carcinoma. Ann. Gastroenterol. Ann Gastroenterol Surg 2018; 2(4):266-73.

11. Fierabracci A, Pellegrino M. The double role of p53 in cancer and autoimmunity and its potential as therapeutic target. Int J Mol Sci 2016; 17(12):1975.

12. Blanchard $P$, Quero L, Pacault V, Schlageter $\mathrm{M}-\mathrm{H}$, Baruch-Hennequin $\mathrm{V}$, Hennequin C. Prognostic significance of anti-p53 and anti-KRas circulating antibodies in esophageal cancer patients treated with chemoradiotherapy. BMC cancer 2012; 12(1):119.

13. Sorrell AD, Espenschied CR, Culver JO, Weitzel JN. Tumor protein p53 (TP53) testing and Li-Fraumeni syndrome. Mol Diagn Ther 2013; 17(1):31-47.

14. Kotler E, Shani O, Goldfeld G, LotanPompan M, Tarcic O, Gershoni A, et al. A systematic p53 mutation library links differential functional impact to cancer mutation pattern and evolutionary conservation. Mol Cell 2018; 71(1):17890. e8.

15. Suppiah, A., A. Alabi, L. Madden, J. Hartley, J. Monson and J. Greenman. "Anti-p53 autoantibody in colorectal cancer: prognostic significance in long- 
term follow-up. Int J Colorectal Dis

2008; 23(6): 595-600.

16. Leo O, Cunningham A, Stern PL. Vaccine immunology. Perspectives in Vaccinology 2011; 1(1):25-59.

17. Suzuki T, Yajima S, Ishioka N, Nanami T, Oshima Y, Washizawa N, et al. Prognostic significance of high serum p53 antibody titers in patients with esophageal squamous cell carcinoma. Esophagus 2018; 15(4):294-300.

18. Byun DJ, Wolchok JD, Rosenberg LM, Girotra M. Cancer immunotherapyimmune checkpoint blockade and associated endocrinopathies. Nat Rev Endocrinol 2017; 13(4):195-207.

19. Kim MP, Lozano G. Mutant p53 partners in crime. Cell Death Differ 2018; 25(1):161-8.

20. Bykov VJ, Eriksson SE, Bianchi J, Wiman KG. Targeting mutant p53 for efficient cancer therapy. Nat Rev Cancer 2018; 18(2):89.

21. Ushigome $M$, Nabeya $Y$, Soda $H$, Takiguchi N, Kuwajima A, Tagawa M, et al. Multi-panel assay of serum autoantibodies in colorectal cancer. Int J Clin Oncol 2018; 23(5):917-23.

22. Áyen Á, Jiménez Martínez Y, Marchal JA, Boulaiz $H$. Recent progress in gene therapy for ovarian cancer. Int $\mathrm{J} \mathrm{Mol}$ Sci 2018; 19(7):1930.

23. Momozawa $\mathrm{Y}$, Iwasaki $\mathrm{Y}$, Parsons MT, Kamatani Y, Takahashi A, Tamura C, et al. Germline pathogenic variants of 11 breast cancer genes in 7,051 Japanese patients and 11,241 controls. Nat Commun 2018; 9(1):1-7.

24. Crawford, L., D. Pim and R. Bulbrook. Detection of antibodies against the cellular protein p53 in sera from patients with breast cancer. Int J Cancer 1982; 30(4): 403-408.

25. Jabir FA, Hoidy WH. No Evaluation of Serum P53 Levels in Iraqi Female Breast Cancer Patients. Asian Pac J Cancer Prev 2017; 18(9):255.

26. Sangrajrang $S$, Arpornwirat $W$, Cheirsilpa A, Thisuphakorn P, Kalalak A, Sornprom $A$, et al. Serum p53 antibodies in correlation to other biological parameters of breast cancer. Cancer Detect Prev 2003; 27(3):182-6.
27. Okada R, Shimada H, Otsuka Y, Tsuchiya $M$, Ishii J, Katagiri T, et al. Serum p53 antibody as a potential tumor marker in extrahepatic cholangiocarcinoma. Surgery Today 2017; 47(12):1492-9.

28. Peyrat J-P, Fournier J, Bonneterre J, Vanlemmens L, Lubin R, Soussi T et al. Prognostic significance of circulating p53 antibodies in patients undergoing surgery for locoregional breast cancer. The Lancet 1995; 345(8950):621-2.

29. Wang W, Qin J-J, Voruganti S, Srivenugopal KS, Nag S, Patil S, et al. The pyrido [b] indole MDM2 inhibitor SP-141 exerts potent therapeutic effects in breast cancer models. Nat Commun 2014; 5(1):1-12.

30. Okada R, Otsuka $Y$, Wakabayashi T, Shinoda M, Aoki T, Murakami M, et al. Six autoantibodies as potential serum biomarkers of hepatocellular carcinoma: A prospective multicenter study. Int $\mathrm{J}$ Cancer 2020; 147(9):2578-86.

31. Hoshino I, Nagata M, Takiguchi N, Nabeya Y, Ikeda A, Yokoi S, et al. Panel of autoantibodies against multiple tumorassociated antigens for detecting gastric cancer. Cancer Science 2017; 108(3):308-15.

32. Takashi S, Satoshi Y, Akihiko O, Naoya Y, Yusuke $\mathrm{T}$, Kentaro $M$, et al. Clinical impact of preoperative serum p53 antibody titers in 1487 patients with surgically treated esophageal squamous cell carcinoma: a multi-institutional study. Esophagus 2020:1-7. doi: 10.1007/s10388-020-00761-6.

33. Mattioni, M., S. Soddu, A. Prodosmo, P. Visca, S. Conti, G. Alessandrini, F.

Facciolo and L. Strigari. Prognostic role of serum p53 antibodies in lung cancer. BMC cancer 2015; 15(1): 148.

34. Shiratori F, Ito M, Yajima S, Suzuki T, Oshima Y, Nanami T, et al. The effectiveness of serum midkine in detecting esophageal squamous cell carcinoma. Esophagus 2019; 16(3):24651.

35. Shimada H, Ochiai T, Nomura F. Titration of serum p53 antibodies in 1085 patients with various types of malignant tumors: a multiinstitutional analysis by the Japan p53 Antibody Research Group. Interdisciplinary International Journal of the American Cancer Society 2003; 97(3):682-9. 
36. Lubin R, B Schlichtholz, JLTeillaud, E Garay, A Bussel, CP Wild, et al. p53 antibodies in patients with various types of cancer: assay, identification, and characterization. Clin Cancer Res 1995; 1:1463-9.

37. Chang $Y$, Liu B, Niu H, Wang Z, Xia S, Li $H$. Value of anti-p53 antibody as a biomarker for hepatocellular carcinoma:
Evidence from a meta-analysis. Medicine 2020; 99(34).e21887.

38. Pedersen J, Gentry-Maharaj A, Fourkala E, Dawnay A, Burnell M, Zaikin A, et al. Early detection of cancer in the general population: a blinded case-control study of p53 autoantibodies in colorectal cancer. Br J Cancer 2013; 108(1):10714. 